\title{
ICT AND CREATIVITY IN ARCHITECTURE TEACHING
}

\author{
M.I. Alba Dorado \\ University of Malaga (SPAIN)
}

\begin{abstract}
At present we observe how the Bologna plan has meant a change to a paradigm focused on competency-based learning. In this context, transversal competences are fundamental and constitute an added value that facilitates and accelerates full integration in the labor market of graduates. Among these transversal competences we find those related to critical thinking, innovation and creativity. The importance of the latter has increased in recent years, receiving greater weight, being declared one of the most important skills in the educational context of the 21 st century. The importance that this creative component acquires in the formation of the future architect as an inherent value in the teaching process implies a completely new teaching approach.
\end{abstract}

Likewise, we are currently attending the expansion of Information and Communication Technologies (ICT) in various aspects of life, including the teacher. This has led to certain technological, audiovisual and computer tools occupy a privileged place in the field of teaching and that, in themselves, are presented as content, objectives and teaching objects.

ICT, due to its multidimensional nature, can offer numerous ways to enhance the development of creativity. These innovative teaching tools generate a high motivating potential given their great attractiveness and constitute an auspicious occasion to provoke significant learning.

The purpose of this communication is to present the results of an educational innovation project developed at the School of Architecture of the University of Malaga, whose main objective is to improve the teaching of university teachers based on the use of ICT in the process teachinglearning from a creative and enriching perspective. Thus, under the title "Information and Communication Technologies (ICT) as support for the development and promotion of creative thinking processes in university teaching" this project has sought to deepen the maximum use of the opportunities that these Resources provide not only for the achievement of pedagogical objectives or improvement of student learning, but also to encourage, stimulate and develop creative, critical and innovative thinking.

The relevance of the development of this project lies on the one hand, in the importance acquired in the training of every architect to generate creative thinking and, on the other hand, in the fact that at present the potential of ICT has not been sufficiently exploited when it comes to achieving creative learning and innovative teaching.

The results obtained through these teaching practices have shown that the use of ICT in architecture teaching encourages creativity in students, allows developing a proactive approach to creativity in the classroom that includes the development of related skills with creative thinking and behavior in students.

Keywords: Architectural Projects, ICT Tools, Critical Discipline, Experimental Pedagogy. 